\title{
Esquadrinhando as relações raciais
}

\author{
Scrutinizing race relations
}

\author{
Petrônio Domingues \\ Professor/Universidade Federal de Sergipe \\ pjdomingues@yahoo.com.br
}

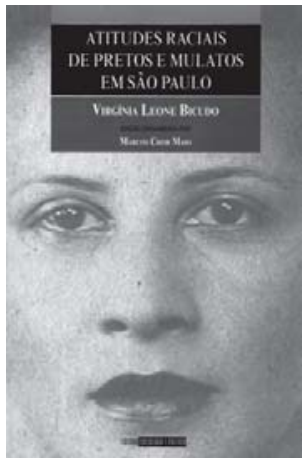

BICUDO, Virgínia Leone. Atitudes raciais de pretos e mulatos em São Paulo. Política, 2010. 192p. São Paulo: Sociologia e Virgínia Leone Bicudo nasceu na cidade de São Paulo, em 1910.
De ascendência negra, filha de Joana Leone e Teófilo Bicudo, teve cinco irmãos. Cedo foi alvo do preconceito de cor (o que a fazia sofrer), mas também cedo demonstrou inclinação para os livros. Estudou na escola do Brás e no Ginásio do Estado e, depois, na tradicional Escola Normal Caetano de Campos, em que concluiu o que mais tarde seria chamado de magistério. Trabalhou como professora em grupos escolares da capital e, posteriormente, matriculou-se no curso de educadores sanitários do Instituto de Higiene de São Paulo. Ao terminá-lo, em 1933, ano da morte de seu pai, foi contratada pela diretoria do Serviço de Saúde Escolar do Departamento de Educação para dar aulas de higiene em educandários da cidade de São Paulo, até que, três anos depois, surgiu a oportunidade, e ela ingressou no curso de graduação em ciências políticas e sociais da Escola Livre de Sociologia e Política (ELSP), instituição pioneira no terreno das ciências sociais no Brasil.

Para uma neta de escravo, significava muito chegar até ali, mas ela queria mais. Bacharelou-se em ciências sociais e políticas em 1938 e tornou-se visitadora psiquiátrica do Serviço de Higiene Mental Escolar da Secretaria de Educação do Estado de São Paulo. No início da década de 1940, começou a lecionar na ELSP as disciplinas higiene mental e psicanálise, junto com Durval Marcondes. Dois anos depois, ingressou na recém-criada Divisão de Estudos Pós-graduados da ELSP, coordenada pelo sociólogo norte-americano Donald Pierson, e formou, juntamente com Gioconda Mussolini e Oracy Nogueira. a primeira turma do mestrado da instituição. Sob a orientação do sociólogo norte-americano, Virgínia Bicudo interessou-se pelos 'estudos de atitudes', na fronteira da sociologia com a psicologia social. A princípio, seu projeto de pesquisa intitulava-se Estudo da consciência de raça entre pretos e mulatos de São Paulo, indicando seu interesse pelo tema das relações raciais. Em 1941 - durante a ditadura do Estado Novo, no plano interno, e o transcurso da Segunda Guerra Mundial, no plano externo - sua pesquisa foi iniciada, e em 1945 ela concluiu a dissertação Atitudes raciais de pretos e mulatos em São Paulo, a primeira pesquisa de mestrado sobre relações raciais defendida numa instituição universitária brasileira. E foi essa pesquisa (que durante décadas circulou em pouquíssimas mãos, para não dizer que ficou esquecida pela intelligentsia brasileira) que se tornou livro. 
A proposta da autora é estudar as atitudes de negros relacionadas à questão racial, em São Paulo. Para tanto, vale-se de mais de trinta entrevistas e estudos de caso (nos distritos de Bela Vista, Santana, Vila Mariana, Barra Funda e Mooca), com dois grupos, um de pretos, outro de mulatos, subdivididos, conforme condição econômica, profissão e nível de instrução, em classe social inferior e classes sociais intermediárias. Virgínia Bicudo também analisa uma associação dos homens de cor e as opiniões de seu jornal, Os descendentes de Palmares. O arcabouço teórico-conceitual de sua pesquisa apoia-se nos pressupostos de sociólogos da Universidade de Chicago (a saber: Robert Park e Ellsworth Faris) e nos postulados de Everett Stonequist, Oracy Nogueira e Donald Pierson.

O livro está estruturado em seis tópicos. No primeiro, Bicudo investiga os 'casos de pretos da classe social inferior' e constata, por meio de depoimentos, clima de desunião, ausência de solidariedade ou mesmo rivalidade entre os indivíduos desse segmento social. Isso se deve, de acordo com a autora, ao complexo de inferioridade que os leva a atitude de antagonismo com pretos e de simpatia com brancos. No segundo tópico, ela examina os 'casos de pretos das classes sociais intermediárias' e observa que suas atitudes, referentes à questão racial, são mais pronunciadas do que as dos pretos da classe social inferior. Sua 'sensibilidade ligada à cor' ficaria, assim, à flor da pele, quer em função dos ressentimentos produzidos pela rejeição dos brancos, quer pelas queixas da falta de solidariedade entre os pretos. Entretanto, os pretos das camadas sociais intermediárias estabeleceriam, desde a infância, contatos primários com os brancos e tenderiam a com eles se identificar, desenvolvendo o que Bicudo define como autoideal de branco, um complexo de inferioridade que compele os pretos das camadas intermediárias a introjetar os ideais do branco e a ver seus 'irmãos de cor' a partir desses ideais; daí a origem de sua frustração e seu isolamento. Isolam-se "do branco para evitar o sofrimento de ser evitado pelo branco em certas situações sociais. Isolam-se do preto em consequência do mesmo sentimento de inferioridade que os leva a lutar pela aceitação do branco. Considerando-se inferior, o negro não pode alcançar a satisfação dos desejos de correspondência e consideração através de outro preto" (p.102).

No terceiro tópico do livro, a autora esquadrinha os 'casos de mulatos da classe social inferior' e verifica que eles têm mais suscetibilidades, no tocante às questões raciais e 'consciência de cor', do que os pretos da mesma classe social, talvez por sua vinculação biológica e social aos dois grupos raciais. Tudo se passa como "se o mulato, sentindo-se com mais direito de ser branco, se tornasse mais consciente das atitudes de restrição do branco" (p.110). No quarto tópico, Bicudo debruça-se sobre os 'casos de mulatos das classes intermediárias' e infere que eles manifestam 'sentimento de inferioridade', esforçando-se no sentido de escapar à categoria 'preto' ou mesmo 'mulato'. Para tanto, evitam a companhia de pretos e se aproximam dos brancos. E, à medida que 'branqueiam' na cor e na personalidade, encontram mais aceitação social.

No quinto tópico, a autora perscruta as "atitudes reveladas numa associação de homens de cor por um dos membros da diretoria". Embora omita o nome verdadeiro da associação, trata-se da Frente Negra Brasileira (1931-1937), e o membro da diretoria é, provavelmente, Francisco Lucrécio. A partir de entrevistas, de documentos produzidos pela Frente Negra e de opiniões emitidas por Os descendentes de Palmares, jornal que, na verdade, se denominava 
A Voz da Raça, Bicudo constata que a Associação de Negros Brasileiros almejava mobilizar os negros a fim de qualificá-los para pugnar contra os obstáculos à ascensão social em consequência da cor. Os meios de que se valeram consistiram em "desenvolver a consciência do grupo; pela divulgação da instrução, combater o negro decaído e antagonista do próprio negro e evitar a atitude de antagonismo contra o branco; conseguir a aceitação do grupo dominante pelos valores profissional e educacional e pela força da política" (p.137). No último tópico são enfocadas as "atitudes reveladas em Os descendentes de Palmares, mensário da Associação de Negros Brasileiros", apurando que os artigos de colaboradores negros e mulatos se destinavam a: "1) promover a solidariedade dos negros, despertando-lhe a consciência de grupo, a fim de reunidos se constituírem em força para a luta competitiva com outros grupos; 2) enaltecer o negro, com o fim de eliminar seu sentimento de inferioridade; 3) difundir a instrução e a educação moral, para colocar o negro em melhores condições culturais na competição com grupos não negros" (p.138).

Na conclusão incluem-se resumo e hipóteses visando a pesquisas futuras, e Bicudo retoma seus principais argumentos acerca das atitudes raciais de pretos e mulatos em São Paulo: sua autoconcepção, a consciência de cor, seu status ocupacional e social, e sua acomodação social. Pode-se acoimar o texto de datado, no que tange ao arcabouço epistemológico, à gramática conceitual e ao repertório léxico; não se pode, porém, deixar de lhe reconhecer importância e arrojo. Importância porque não se trata apenas da dissertação de mestrado sobre as relações raciais precursora em instituição universitária brasileira, mas, salvo engano, porque consiste na primeira dissertação defendida por uma mulher afro-brasileira. Importância pelas qualidades imanentes da pesquisa: o rigor no levantamento (e cotejamento) das fontes, a abordagem interdisciplinar (cruzando sociologia, antropologia e psicologia social), a sensibilidade analítica e o estilo deliberadamente científico. Importância porque Bicudo procura afirmar a "questão racial" como campo de estudo (p.157) e, enquanto tal, sua pesquisa contribuiu para o processo de institucionalização das ciências sociais no país. E, se isso não bastasse, seu empreendimento investigativo caracterizou-se pelo arrojo. Em época na qual intelectuais, jornalistas e políticos propalavam o jargão de que não havia discriminação racial no Brasil ou veiculavam o discurso de que o preconceito de classe era determinante por aqui, Bicudo apresenta explicação inovadora, postulando a ideia de que o Brasil desenvolveu, sim, discriminação contra o preto e o mulato, discriminação específica, baseada na cor. E, contrariando até mesmo seu reputado orientador, Donald Pierson, a socióloga estabelece que, além da classe, a cor era marcador importante na geração de desigualdades sociais. Em vez de harmonia racial, as relações entre negros e brancos, ao menos em São Paulo, seriam permeadas de competição, tensões, conflitos e preconceito de cor, mesmo quando se dirimiam as diferenças sociais.

Por tudo isso, a publicação da obra, pela editora da Fundação Escola de Sociologia e Política de São Paulo, deve ser saudada. Como assinala Rodrigo Estramanho de Almeida, diretor da editora, a publicação é uma homenagem à autora, que foi aluna e professora da instituição. É verdade que se trata de homenagem póstuma (Virgínia Bicudo faleceu em 2003), mas justa e merecida. Dignos de nota são o prefácio de Elide Rugai Bastos e a ampla (e elucidativa) introdução de Marcos Chor Maio. Este, aliás, foi o organizador da edição, 
que inclui caderno de imagens documentando a trajetória da autora, em seus primeiros tempos, na Escola de Sociologia e Política, e como psicanalista, carreira profissional pela qual Bicudo também incursionou depois do mestrado. Oxalá a publicação tire Atitudes raciais de pretos e mulatos em São Paulo do ostracismo para ocupar seu devido lugar na história do pensamento social brasileiro. 